(C) The Author(s), 2021. Published by Cambridge University Press on behalf of The Nutrition Society. This is an Open Access article distributed under the terms of the Creative Commons Attribution licence (http://creativecommons.org/licenses/by/4.0/), which permits unrestricted re-use, distribution, and reproduction in any medium, provided the original work is properly cited.

\title{
Sarcopenia and homocysteine: is there a possible association in the elderly? A narrative review
}

\author{
Rachele De Giuseppe ${ }^{1 *}$, Chiara Elena Tomasinelli ${ }^{1}$, Alessandra Vincenti ${ }^{1}$, Ilaria Di Napoli ${ }^{1}$, \\ Massimo Negro ${ }^{2}$ and Hellas Cena ${ }^{1,3}$ \\ ${ }^{1}$ Laboratory of Dietetics and Clinical Nutrition, Department of Public Health, Experimental and Forensic Medicine, University of \\ Pavia, Pavia, Italy \\ ${ }^{2}$ Centro di Ricerca Interdipartimentale nelle Attività Motorie e Sportive (CRIAMS)-Sport Medicine Centre, University of Pavia, \\ Voghera, Italy \\ ${ }^{3}$ Clinical Nutrition and Dietetics Service, Unit of Internal Medicine and Endocrinology, ICS Maugeri IRCCS, University of Pavia, \\ Pavia, Italy
}

\section{Abstract}

Background: Sarcopenia (SA) is a progressive skeletal muscle disorder, associated with increased risk of adverse outcomes, including falls, fractures, physical disability and mortality. Several risks factors may contribute to the development of SA in the elderly; among them, nutrition plays a key role in muscle health. The elderly are at risk of inadequate intake in terms of micronutrients affecting muscle homeostasis, such as B vitamins, related to homocysteine (Hcy) metabolism.

Objectives and methods: This narrative review analysed the association between increased Hcy levels and SA, according to the criteria of the International Working Group on Sarcopenia, the European Working Group on Sarcopenia in Older People and the Asian Working Group for Sarcopenia. The authors focused not only on SA per se but also on exploring the association between increased Hcy levels and components of SA, including muscle mass, muscle strength and physical performance.

Results: Results are inconsistent, except for muscle mass, showing no significant associations with Hcy levels.

Conclusions: Few and conflicting data emerged in this review on the association between SA and increased Hcy levels due to numerous differences between studies that change the significance of the association of Hcy and SA, as well as the muscle strength, muscle mass and physical performance. Furthermore, because the ageing process is not uniform in the population owing to differences in genetics, lifestyle and general health, chronological age fails to address the observed heterogeneity among the 'elderly' of the studies reported in this revision. Therefore, further studies are still needed.

\section{Keywords: Sarcopenia: Elderly: Homocysteine: Muscle strength: Muscle mass: Physical performance}

(Received 29 September 2020; revised 18 April 2021; accepted 23 April 2021; accepted manuscript published online 30 April 2021)

\section{Introduction}

Sarcopenia (SA) is defined as an age-related loss of muscle mass and function ${ }^{(1)}$.

Research focusing on the definition and diagnostic criteria of SA has been conducted all over the world, leading to publication and update of international consensus ${ }^{(1-3)}$, including the recent International Working Group on Sarcopenia (IWGS) ${ }^{(2)}$, published in 2011; the European Working Group on Sarcopenia in Older People (EWGSOP) ${ }^{(4)}$, published in 2010 and updated in 2019 ${ }^{(1)}$; and the Asian Working Group for Sarcopenia $(\mathrm{AWGS})^{(5)}$, published in 2014 and updated in $2020^{(3)}$ (Table 1).
The IWGS defined SA as the combination of low whole-body or appendicular fat-free mass and poor physical function ${ }^{(2)}$. On the contrary, the updated version of the EWGSOP (EWGSOP2) reported a new 'operational' definition of SA, adopting poor muscle strength as the primary criterion for SA diagnosis ${ }^{(1)}$. Specifically, SA is 'probable' when poor muscle strength is detected, while SA diagnosis is 'confirmed' when there is a concomitant loss of muscle quantity/quality ${ }^{(1)}$. Besides, when poor muscle strength, loss of muscle quantity/quality and low physical performance are detected, SA is considered severe ${ }^{(1)}$. The updated version of AWGS (AWGS2) decided against following

*Corresponding author: Rachele De Giuseppe, Laboratory of Dietetics and Clinical Nutrition, Department of Public Health, Experimental and Forensic Medicine, University of Pavia; via Bassi 21, 27100 Pavia, Italy. Email: rachele.degiuseppe@unipv.it. Telephone number: 0039-0382987544; Fax number: 0039-0382987191 
Table 1. Algorithms for SA diagnosis. In blue: the relevant algorithms for SA diagnosis proposed by the European Working Group on Sarcopenia in Older People (EWGOS2)(1), the International Working Group on Sarcopenia $\left(\right.$ IWGS) ${ }^{(2)}$ and the Asian Working Group for Sarcopenia (AWGS2)(3). In grey: the old version of the algorithm for SA diagnosis proposed by the European Working Group on Sarcopenia in Older People (EWGOS) ${ }^{(4)}$ and the Asian Working Group for Sarcopenia (AWGS) ${ }^{(5)}$

\begin{tabular}{|c|c|c|c|c|}
\hline Consensus & Definition of SA & Probable SA & Confirmed SA & Severe SA \\
\hline $\begin{array}{l}\text { European Working Group on Sarcopenia } \\
\text { in Older People } \\
\text { (EWGSOP2) } \\
\text { Cruz-Jentoft } \\
\text { et al. } 2019^{(1)}\end{array}$ & $\begin{array}{l}\text { Loss of muscle strength plus } \\
\text { reduced muscle quantity or } \\
\text { quality }\end{array}$ & $\begin{array}{l}\text { Low muscle strength } \\
\text { - Handgrip strength } \\
\text { (M: <27 kg; F: <16 kg) }\end{array}$ & $\begin{array}{l}\text { Low muscle strength } \\
\text { - Handgrip strength } \\
\text { (M: }<27 \mathrm{~kg} ; \mathrm{F}:<16 \mathrm{~kg}) \\
+ \\
\text { Low muscle mass (quantity/quality) } \\
\text { - ASM } / \mathrm{h}^{2} \\
\left(\mathrm{M}:<7.0 \mathrm{~kg} / \mathrm{m}^{2}, \mathrm{~F}:<5.5 \mathrm{~kg} / \mathrm{m}^{2}\right)\end{array}$ & $\begin{array}{l}\text { Low muscle strength } \\
\text { - Handgrip strength } \\
\text { (M: }<27 \mathrm{~kg} ; \mathrm{F}:<16 \mathrm{~kg}) \\
+ \\
\text { Low muscle mass (quantity/quality) } \\
\text { - ASM } / \mathrm{h}^{2} \\
\left(\mathrm{M}:<7 \cdot 0 \mathrm{~kg} / \mathrm{m}^{2}, \mathrm{~F}:<5.5 \mathrm{~kg} / \mathrm{m}^{2}\right) \\
+ \\
\text { Low physical performance } \\
\text { - Gait speed test: } \leq 0.8 \mathrm{~m} / \mathrm{s} \\
\text { - SPPB } \leq 8\end{array}$ \\
\hline $\begin{array}{l}\text { International Working Group on Sarcopenia } \\
\text { (IWGS) } \\
\text { Fielding et al. 2011(2) }\end{array}$ & $\begin{array}{l}\text { Low whole-body or appendicular } \\
\text { fat-free mass in combination } \\
\text { with poor physical functioning }\end{array}$ & $\begin{array}{l}\text { Low physical performance } \\
\text { - Gait speed test: } \leq 1 \mathrm{~m} / \mathrm{s}\end{array}$ & $\begin{array}{l}\text { Low physical performance } \\
\text { - Gait speed test: } \leq 1 \mathrm{~m} / \mathrm{s} \\
+ \\
\text { Low muscle mass } \\
\text { - ASM } / \mathrm{h}^{2} \\
\left(\mathrm{M}:<7.23 \mathrm{~kg} / \mathrm{m}^{2}, \mathrm{~F}:<5 \cdot 67 \mathrm{~kg} / \mathrm{m}^{2}\right)\end{array}$ & \\
\hline $\begin{array}{l}\text { Asian Working Group } \\
\text { for Sarcopenia } \\
\text { (AWGS2) } \\
\text { Chen et al. } 2020^{(3)}\end{array}$ & $\begin{array}{l}\text { Age-related loss of skeletal } \\
\text { muscle mass plus loss of } \\
\text { muscle strength and/or } \\
\text { reduced physical perfor- } \\
\text { mance }\end{array}$ & $\begin{array}{l}\text { Low muscle strength } \\
\text { - Handgrip strength } \\
\text { (M: }<28 \mathrm{~kg} ; \mathrm{F}:<18 \mathrm{~kg}) \\
\text { OR } \\
\text { Low physical performance } \\
\text { - } 5 \text {-time chair stand test } \\
\quad(\geq 12 \mathrm{~s}) \\
\text {-6-m walk: }<1.0 \mathrm{~m} / \mathrm{s} \\
\text { - SPPB: } \leq 9\end{array}$ & $\begin{array}{l}\text { Low muscle mass } \\
\text { - ASM } / \mathrm{h}^{2} \\
\left(\mathrm{M}:<7 \cdot 0 \mathrm{~kg} / \mathrm{m}^{2}, \mathrm{~F}:<5 \cdot 7 \mathrm{~kg} / \mathrm{m}^{2}\right) \\
+ \\
\text { Low muscle strength } \\
\text { - Handgrip strength } \\
\text { (M: }<28 \mathrm{~kg} ; \mathrm{F}:<18 \mathrm{~kg}) \\
\text { OR } \\
\text { Low muscle mass } \\
\text { - ASM } / \mathrm{h}^{2} \\
\left.\text { (M: }<7 \cdot 0 \mathrm{~kg} / \mathrm{m}^{2}, \mathrm{~F}:<5 \cdot 7 \mathrm{~kg} / \mathrm{m}^{2}\right) \\
+ \\
\text { Low physical performance } \\
\text { - } 5 \text {-time chair stand test }(\geq 12 \mathrm{~s}) \\
\text { - } 6-\mathrm{m} \text { walk: }<1.0 \mathrm{~m} / \mathrm{s} \\
\text { - SPPB: } \leq 9\end{array}$ & $\begin{array}{l}\text { Low muscle strength } \\
\text { - Handgrip strength } \\
\text { (M: }<28 \mathrm{~kg} ; \mathrm{F}:<18 \mathrm{~kg}) \\
+ \\
\text { Low muscle mass } \\
\text { - ASM } / \mathrm{h}^{2} \\
\left(\mathrm{M}:<7 \cdot 0 \mathrm{~kg} / \mathrm{m}^{2}, \mathrm{~F}:<5 \cdot 7 \mathrm{~kg} / \mathrm{m}^{2}\right) \\
+ \\
\text { Low physical performance } \\
\text { - } 5 \text {-time chair stand test }(\geq 12 \mathrm{~s}) \\
\text {-6-m walk: }<1.0 \mathrm{~m} / \mathrm{s} \\
\text { SPPB: } \leq 9\end{array}$ \\
\hline $\begin{array}{l}\text { European Working Group on Sarcopenia } \\
\text { in Older People } \\
\text { (EWGSOP) } \\
\text { Cruz-Jentoft et al. } 2010^{(4)}\end{array}$ & $\begin{array}{l}\text { Progressive and generalised } \\
\text { loss of skeletal muscle mass } \\
\text { plus reduced muscle strength } \\
\text { or physical performance }\end{array}$ & $\begin{array}{l}\text { Low muscle mass } \\
\text { - SMl/ } \mathrm{h}^{2} \\
\left(\mathrm{M}:<8.87 \mathrm{~kg} / \mathrm{m}^{2}\right. \\
\left.\quad \mathrm{F}:<6.42 \mathrm{~kg} / \mathrm{m}^{2}\right)\end{array}$ & $\begin{array}{l}\text { Low muscle mass } \\
-\mathrm{SMl} / \mathrm{h}^{2} \\
\left(\mathrm{M}:<8 \cdot 87 \mathrm{~kg} / \mathrm{m}^{2}, \mathrm{~F}:<6 \cdot 42 \mathrm{~kg} / \mathrm{m}^{2}\right) \\
+ \\
\text { Low muscle strength } \\
\text { - Handgrip strength } \\
\text { (M: }<30 \mathrm{~kg} ; \mathrm{F}:<20 \mathrm{~kg}) \\
\text { OR } \\
\text { Low muscle mass } \\
\text { - } \mathrm{SMl} / \mathrm{h}^{2} \\
\left(\mathrm{M}:<8.87 \mathrm{~kg} / \mathrm{m}^{2}, \mathrm{~F}:<6 \cdot 42 \mathrm{~kg} / \mathrm{m}^{2} \text { ) }\right. \\
+ \\
\text { Low physical performance } \\
\text { - SPPB } \leq 8 \\
6-\mathrm{m} \text { walk: }<1.0 \mathrm{~m} / \mathrm{s}\end{array}$ & $\begin{array}{l}\text { Low muscle mass } \\
-\mathrm{SMl} / \mathrm{h}^{2} \\
+ \\
\text { Low muscle strength } \\
\text { • Handgrip strength } \\
\text { (M: }<30 \mathrm{~kg} ; \mathrm{F}:<20 \mathrm{~kg} \text { ) } \\
+ \\
\text { Low physical performance } \\
\text { - SPPB } \leq 8 \\
6-\mathrm{m} \text { walk: }<1.0 \mathrm{~m} / \mathrm{s}\end{array}$ \\
\hline
\end{tabular}


a recent trend to consider all muscle wasting as SA, retaining its original definition of 'age-related loss of skeletal muscle mass plus loss of muscle strength and/or reduced physical performance', without reference to comorbidity ${ }^{(3)}$. Thus, SA is defined as 'probable' if poor muscle strength is detected with or without reduced physical performance, while SA diagnosis is confirmed if a loss of muscle mass is combined with poor muscle strength; this, when combined with low physical performance defines 'severe sarcopenia'(3).

To date, SA is formally acknowledged as a muscle disease (muscle failure) with an International Classification of Diseases, Tenth Revision, Clinical Modification (ICD-10-MC) Diagnosis Code for billing and claims reimbursement in some countries ${ }^{(1)}$.

Evidence supports the association between SA and several negative health outcomes, including increased risk of falls and fractures $^{(6)}$ and osteoporosis ${ }^{(7)}$; impairment in daily activities and personal care ${ }^{(8)}$; association with cardiovascular, respiratory diseases ${ }^{(9)}$, cognitive impairment ${ }^{(10)}$, mobility disorders and poor quality of life ${ }^{(11)}$; and increased risk of death ${ }^{(12)}$. Besides, SA increases healthcare costs, raising hospitalisation risk, length of stay and hospitalisation costs ${ }^{(1)}$.

Several risks factors may contribute to the development of SA in the elderly, including sedentariness, hospitalisation, immobilisation and prolonged bed rest ${ }^{(13)}$. Moreover, certain diseases can promote the development of SA throughout chronic inflammation and metabolic derangements, such as hormonal pathway disorders (e.g. testosterone, estrogens, growth hormone, insulinlike growth factor-1), malignancies, chronic inflammatory diseases and advanced organ failure (heart, lung, liver, kidney or brain $)^{(13)}$. Finally, nutrition and hydration play a very important role in muscle health by influencing myocyte homeostasis and energy metabolism ${ }^{(14)}$. Nowadays, evidence shows that the elderly are at risk of inadequate intake in terms of energy, macronutrients and micronutrients with a negative impact on muscle homeostasis ${ }^{(15,16)}$. Inadequate energy and/or protein intake, malabsorption, gastrointestinal disorders or drug-nutrient interactions have been related to $\mathrm{SA}^{(15)}$. In particular, low levels of $\mathrm{B}$ vitamins, more common as people get older ${ }^{(17)}$, are related to homocysteine (Hcy) metabolism ${ }^{(18)}$, a sulphur-containing amino acid involved in both re-methylation ( $\mathrm{B}_{12^{-}}$and $\mathrm{B}_{9}$-dependent) and trans-sulphuration $\left(\mathrm{B}_{6}\right.$-dependent) pathways ${ }^{(18)}$. Hcy levels above the relevant cut-off value (hyperhomocysteinemia, HHcy) may be associated with several consequent diseases, including cardiovascular disease, neurodegenerative disease, peripheral neuropathy, renal failure and hypothyroidism ${ }^{(18)}$. Besides, HHcy might be associated with fractures, disability, frailty, slow gait speed, poor balance and poor physical function ${ }^{(16)}$. The recent scientific opinion on Dietary Reference Values for cobalamin of the European Food Safety Authority Panel on Dietetic Products, Nutrition, and Allergies ${ }^{(19)}$ has proposed acceptable upper reference limits for plasma Hcy levels ranging from 9 to $16 \mu \mathrm{M}$, although a concentration above $15 \mu \mathrm{M}$ in adults is used as an indicator of HHcy. Similarly, Malinowska and colleagues ${ }^{(20)}$ classified several types of HHcy: severe, for concentrations higher than $100 \mu \mathrm{M}$; intermediate, for concentrations between 31 and $100 \mu \mathrm{M}$; moderate, for concentrations of $16-30 \mu \mathrm{M}$; and a reference total plasma Hcy range as $5-15 \mu \mathrm{M}$ (mean, $10 \mu \mathrm{M})$. 
Increased Hcy levels have many contributory causes, including lifestyle factors (smoking, alcohol use and caffeine consumption); poor nutrition with special focus on folate, vitamin $\mathrm{B}_{12}$ and vitamin $\mathrm{B}_{6}$ depletion; impaired kidney function; and inborn errors of metabolism involving enzymes such as cystathionine$\beta$-synthase, methionine synthase and methylenetetrahydrofolate reductase (MTHFR $)^{(19)}$. Also, alimentary tract disorders connected with impaired absorption of vitamins $\mathrm{B}_{6}, \mathrm{~B}_{12}$ and folic acid may play an important role ${ }^{(20)}$. Ethnicity also might indirectly influence Hcy levels; in fact, MTHFR gene polymorphism involves the substitution of cytosine by thymine in position 677 (C677 $\rightarrow$ T) leading to the synthesis of a thermolabile enzyme form with decreased activity. The prevalence of this mutation is race dependent: in Asian and Caucasian populations there are $50 \% \mathrm{C} / \mathrm{T}$ heterozygotes and $10-13 \% \mathrm{~T} / \mathrm{T}$ homozygotes, while in the Afro-American population this polymorphism is rare ${ }^{(20)}$.

Besides, the dependence of Hcy levels on age could result from the decline of the glomerular filtration rate with increasing age $^{(20)}$. Refsum and colleagues ${ }^{(21)}$, based on 95th-97.5th percentiles of Hcy concentration in presumably healthy populations from large studies, proposed the following upper reference limits for populations not supplemented with folate: $15 \mu \mathrm{mol} / 1$ for older children ( $\geq 15$ years) and adults up to 65 years and $20 \mu \mathrm{mol} / 1$ for older adults ( $\geq 66$ years), and $10 \mu \mathrm{mol} / \mathrm{l}$ for pregnancy.

Starting from the evidence that nutrition, including an adequate intake of micronutrients such as metabolically Hcyrelated $\mathrm{B}$ vitamins, affects muscle homeostasis ${ }^{(14-16)}$ and that the elderly are at risk of low vitamin B levels, the aim of this narrative review was to speculate about the relationship between SA and Hcy per se and the relationship between the Hcy levels and SA components (muscle strength, muscle mass and physical performance) in elderly, according to the different consensus for SA $\operatorname{diagnosis}^{(1-5)}$.

\section{Methods}

Intent on exploring a positive association between Hcy levels and SA, according to the different algorithm for SA diagnosis ${ }^{(1-5)}$, the authors collected articles including longitudinal, double-blind, randomised and placebo-controlled trials, published in the English language in the last 10 years, through a search on PubMed.

The following keywords were used for the literature search: elderly, sarcopenia, muscle mass, muscle strength, physical performance, HHcy, vitamin $\mathrm{B}_{12}$, folate.

As regards the selection of the study population, the age range for defining the 'elderly' subjects was not established $a$ priori, but only the studies in which the subjects were defined as 'elderly' or 'older' in the title or abstract were included.

All studies involving subjects affected by SA, according to the relevant diagnostic criteria adopted by the professional societies (such as EWGSOP, AWGS, IWGS, Table 1) ${ }^{(1-5)}$, were considered. Additionally, studies that did not provide a diagnosis of SA but also evaluated the relationship between Hcy levels and some of the SA diagnostic criteria (e.g. muscle strength and/or muscle mass and/or physical performance) were also included.

For each article, type of study, characteristics of the population, aims, assessment of physical functioning, laboratory findings and outcomes in terms of association between Hcy levels and SA were defined. Each article considered eligible was retrieved in the full text whenever available.

Data extrapolated from the studies were collected in two tables (Tables 2 and 3). Particularly, Table 2 presents the summarised studies highlighting Hcy levels and SA relationship per se, while Table 3 reports articles exploring Hcy levels and SA diagnostic criteria (e.g. muscle strength and/or muscle mass and/or and physical performance).

\section{Results}

\section{Hcy and sarcopenia}

Few studies ${ }^{(22-26)}$ explored the association between Hcy levels and SA per se in older and sarcopenic adults. Only Lee et $a l^{(26)}$ defined SA according to the new AWGS2 criteria $^{(3)}$, while the other authors ${ }^{(22-25)}$ defined SA in the elderly according to the old version of $\mathrm{EWGSOP}^{(4)}$ and $\mathrm{AWGS}^{(5)}$.

In the Maastricht Sarcopenia Study (MaSS; clinicaltrials.gov \#NCT01820988), ter Borg et al. ${ }^{(22)}$ conducted a cross-sectional analysis in 227 community-dwelling older adults (median age 74 years), with the purpose of comparing the differences between nutrient intake (habitual dietary intake assessed by using a food frequency questionnaire) and biochemical markers of nutritional status (e.g. Hcy, 25-OH-vitamin D, magnesium, n-3 fatty acids, n- 6 fatty acids and $\alpha$-tocopherol) in sarcopenic versus non-sarcopenic older adults. The authors referred to the algorithm of the EWGSOP ${ }^{(4)}$ for SA definition. Data reported SA in fifty-three participants (23\%); Hcy levels (cut-off value $<15 \mu \mathrm{mol} / \mathrm{l}$ ) were $27 \%$ higher in the sarcopenic group than the non-sarcopenic one $(15 \cdot 2 \pm 4 \cdot 2 \mu \mathrm{mol} / \mathrm{l}$ versus $12 \cdot 1 \pm 7 \cdot 9 \mu \mathrm{mol} / \mathrm{l}$; $p<0 \cdot 001$, respectively), confirming the observed inadequate vitamin B intake in sarcopenic elderly ${ }^{(22)}$. Moreover, $33 \%$ and $16 \%$ of the sample showed Hcy values above the cut-off, respectively, in the sarcopenic group and the non-sarcopenic group ${ }^{(22)}$.

Lee et al. ${ }^{(26)}$, in a cross-sectional analysis, confirmed ter Borg and colleagues' results ${ }^{(22)}$, as to the positive association between increased Hcy levels and SA, defined according to AWGS2 criteria $^{(3)}$. The authors explored the association between SA and two inflammatory markers related to vascular ageing (Hcy and highsensitivity C-reactive protein, hsCRP) in 1582 middle-age and older community-dwelling adults (mean age $64 \cdot 0 \pm 9 \cdot 2$ years) from the first wave of I-Lan Longitudinal Aging Study cohort (ILAS) ${ }^{(26)}$. ILAS was a prospective population-based cohort study, aimed at investigating the interplay between SA, frailty and cognitive functioning, health behaviours and biochemistry profiles $^{(24)}$. Results reported that these inflammatory biomarkers levels were significantly higher $(p=0 \cdot 008$, for Hcy levels) in subjects with $\mathrm{SA}^{(26)}$. Notably, $\log (\mathrm{Hcy})$ per standard deviation increase was significantly $(p=0.002)$ associated with SA in the crude model (odds ratio (OR) 1.4; $95 \%$ CI 1.1, 1.7), and a similarly positive and significant association (OR 2.5; $95 \%$ CI 1.4, 4.4; $p=0.003)$ was found in high versus low Hcy levels for SA ${ }^{(24)}$. Besides, stronger association between Hcy levels and SA was noted in younger subjects (OR $4 \cdot 1,95 \%$ CI $1 \cdot 1,15 \cdot 8 ; p=0 \cdot 001$ ), women (OR $4.7 ; 95 \%$ CI $1.8,11 \cdot 8 ; p=0.001$ ), non-smokers (OR $4.8 ; 95 \%$ CI $3.3,9 \cdot 9 ; p<0 \cdot 001)$ and subjects with lower disease burden (OR 3.0; $95 \%$ CI 0.8, 10.9; $p=0 \cdot 09)^{(26)}$. 


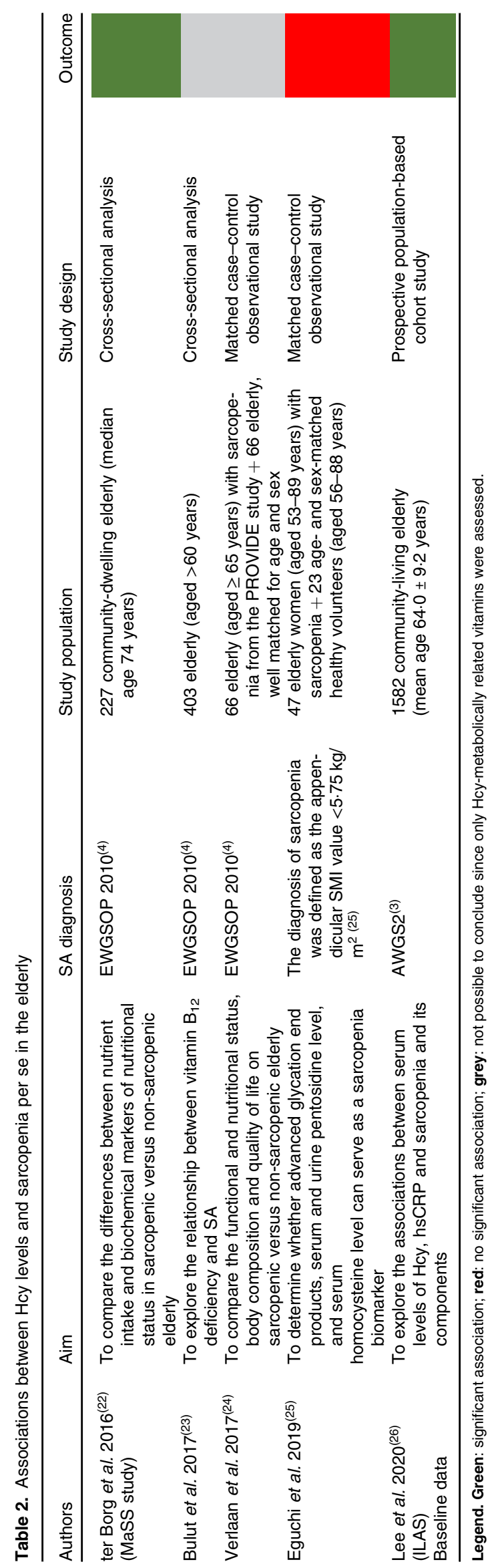

Contrary to what suggested by the two aforementioned studies $^{(22,26)}$, the observational matched case-control study conducted by Eguchi et al. ${ }^{(25)}$ reported no significant association between Hcy levels and SA. Indeed, the authors investigated whether advanced glycation end-products, serum $(\mu \mathrm{g} / \mathrm{ml})$ and urine ( $\mu \mathrm{g} / \mathrm{mg} \mathrm{CRE}$ ) pentosidine levels, serum 1,25(OA)2D (pg/ $\mathrm{ml})$ and $25(\mathrm{OH}) \mathrm{D}(\mathrm{ng} / \mathrm{ml})$ levels and serum Hcy (nmol/ml) levels may serve as biomarkers of SA in forty-seven elderly Japanese women with SA (range 53-89 years), and twenty-three age- and sex-matched healthy volunteers. SA diagnosis among women was established by the appendicular skeletal mass index (the sum of the arm and leg lean mass; $\mathrm{kg} /$ height $(\mathrm{m})^{2}$ ), evaluated by using a multifrequency bioelectrical impedance analyser ${ }^{(25)}$. When the appendicular skeletal mass index value was less than $5.75 \mathrm{~kg} / \mathrm{m}^{2}$, women were considered affected by SA, according to Janssen et al. ${ }^{(27)}$. In this case, despite pentosidine serum levels being significantly higher in the SA group than in the controls $(p<0.05)$, none of the other biochemical markers, including Hcy $(p=0.393)$, showed significant differences between the two groups ${ }^{(25)}$. Moreover, no correlation of skeletal muscle mass with biochemical markers, including Hcy, was detected ${ }^{(25)}$.

Recently, Bulut and colleagues ${ }^{(23)}$ investigated in 403 elderly ( $>60$ years of age) the relationship between vitamin $\mathrm{B}_{12}$ deficiency $(<400 \mathrm{pg} / \mathrm{ml})$ and SA, according to the EWGSOP ${ }^{(4)}$, without measuring plasma Hcy levels and assuming increased Hcy levels due to vitamin B deficiency. The authors identified SA in $24.8 \%$ and $32.0 \%$ of male and female patients, respectively, and reported that $31.6 \%$ of subjects with vitamin $B_{12}$ lower than $400 \mathrm{pg} / \mathrm{ml}$ presented SA. This percentage was significantly higher $(p<0.02)$ when compared with the proportion of sarcopenic subjects with vitamin $B_{12}$ levels above the cut-off value (20.2\%), suggesting that SA might be related to vitamin $\mathrm{B}_{12}$ deficiency ${ }^{(23)}$.

In the same year, Verlaan and colleagues ${ }^{(24)}$ conducted a matched case-control observational cohort study on older adults with SA comparing them with non-sarcopenic controls. Subjects with SA, defined according to the EWGSOP criteria $^{(4)}$, were selected from the PROVIDE study, a multicenter randomised controlled trial, investigating the effect of vitamin D and leucine-enriched whey protein 13-week supplementation on muscle mass, strength and function in older adults with SA ( $n$ =380). In this study, the authors ${ }^{(24)}$ compared functional and nutritional status (nutritional intake and vitamin D, $\alpha$-tocopherol, folate and vitamin $\mathrm{B}_{12}$ measurement), body composition and quality of life in sixty-six sarcopenic versus sixty-six non-sarcopenic elderly (aged $\geq 65$ years), according to the 2010 SA diagnostic criteria ${ }^{(4)}$. As Bulut et al. ${ }^{(23)}$, authors did not directly assess Hcy levels, but they hypothesised increased Hcy levels due to vitamin $B$ deficiency ${ }^{(24)}$. Vitamin $B_{12}$ intake was significantly lower in the sarcopenic sample than in the non-sarcopenic controls ( $22 \%$ different); this was also confirmed by serum vitamin $\mathrm{B}_{12}$ concentrations; there was a significantly higher percentage of SA older adults $(26 \%)$ with vitamin $\mathrm{B}_{12}$ deficiency, corresponding to levels below cut-off $(<200 \mathrm{pmol} / \mathrm{l})$, compared with non-sarcopenic ones $(11 \%)^{(24)}$.

Considering the studies mentioned above ${ }^{(22-26)}$, no firm conclusions can be drawn on the relationship between increased Hcy levels and SA. Contrary to what was reported by ter Borg et $a l .{ }^{(22)}$ and Lee et $a l .{ }^{(26)}$, Eguchi et $a l .{ }^{(25)}$ did not report any 
Table 3. Associations between Hcy levels and different aspects of physical functioning: muscle mass, grip strength and physical performance, in elderly

Outcome

Significant association between Hcy levels and

\begin{tabular}{|c|c|c|c|c|c|c|}
\hline Authors & Aim & Study population (ethnicity) & Study design & muscle mass & muscle strength & performance \\
\hline Bulut et al. $2017^{(23)}$ & $\begin{array}{l}\text { To explore the relationship between vitamin } B_{12} \text { deficiency } \\
\text { and } S A\end{array}$ & 403 elderly, (aged >60 years) & Cross-sectional analysis & & & \\
\hline $\begin{array}{l}\text { Swart et al. } 2013^{(29)} \\
\text { (LASA study) }\end{array}$ & $\begin{array}{l}\text { To examine the relation between Hcy levels and muscle } \\
\text { mass, grip strength, functional limitations and falling }\end{array}$ & $\begin{array}{l}1301 \text { elderly } \\
\text { (aged } \geq 65 \text { years) }\end{array}$ & $\begin{array}{l}\text { Longitudinal study } \\
\text { (3-year follow-up) }\end{array}$ & & $\begin{array}{l}\text { Men } \\
\text { (baseline) }\end{array}$ & $\begin{array}{l}\text { Men/women } \\
\text { (baseline) } \\
\text { Women } \\
\text { (follow-up) }\end{array}$ \\
\hline $\begin{array}{l}\text { Elshorbagy et al. } \\
2008^{(30)}\end{array}$ & $\begin{array}{l}\text { To investigate the association of plasma total cysteine } \\
\text { and Hcy levels with lean and fat mass, also exploring } \\
\text { changes in predicted body composition }\end{array}$ & $\begin{array}{l}7038 \text { middle-age } \\
\text { and elderly }\end{array}$ & $\begin{array}{l}\text { Longitudinal study } \\
\text { (6-year follow-up) }\end{array}$ & & & \\
\hline $\begin{array}{l}\text { Swart et al. } 2013^{(33)} \\
\text { (B-PROOF study) } \\
\text { Baseline data }\end{array}$ & $\begin{array}{l}\text { To explore the association of } \\
\text { (i) Hcy plasma levels, } \\
\text { (ii) the MTHFR 677C-T polymorphism } \\
\text { with muscle mass, handgrip strength, physical perfor- } \\
\text { mance and postural sway }\end{array}$ & $\begin{array}{l}2919 \text { elderly } \\
\text { (aged } \geq 65 \text { years) }\end{array}$ & $\begin{array}{l}\text { Double-blind, randomised, } \\
\text { placebo-controlled trial }\end{array}$ & & Women & $\begin{array}{l}\text { Women } \\
677 \mathrm{CC} \text { and } \\
677 \mathrm{CT} \\
\text { genotype }\end{array}$ \\
\hline Atkins et al. 2014(35) & $\begin{array}{l}\text { To explore associations between low muscle mass and } \\
\text { lifestyle, dietary and } \\
\text { cardio-metabolic risk factors, markers of inflammation, } \\
\text { endothelial dysfunction and coagulation }\end{array}$ & $\begin{array}{l}4252 \text { elderly men (aged 60-79 } \\
\text { years) }\end{array}$ & $\begin{array}{l}\text { Cross-sectional } \\
\text { study }\end{array}$ & & & \\
\hline $\begin{array}{l}\text { ter Borg et al. } 2018^{(22)} \\
\text { (MaSS study) }\end{array}$ & $\begin{array}{l}\text { To investigate whether there is an association between } \\
\text { biochemical nutrient status markers, muscle parameters } \\
\text { and SA }\end{array}$ & $\begin{array}{l}227 \text { community-dwelling elderly } \\
\text { (aged } \geq 65 \text { years) }\end{array}$ & Cross-sectional study & $\begin{array}{l}\text { Unadjusted for } \\
\text { the potential } \\
\text { covariates }\end{array}$ & & $\begin{array}{l}\text { Unadjusted for } \\
\text { the potential } \\
\text { covariates }\end{array}$ \\
\hline $\begin{array}{l}\text { Lee et al. } 2020^{(26)} \\
\text { (ILAS) } \\
\text { Baseline data }\end{array}$ & $\begin{array}{l}\text { To explore the associations between serum levels of Hcy, } \\
\text { hsCRP and SA and its components }\end{array}$ & $\begin{array}{l}1582 \text { community-living elderly } \\
\text { (mean age } 64.0 \pm 9.2 \text { years) }\end{array}$ & $\begin{array}{l}\text { Prospective population- } \\
\text { based cohort study }\end{array}$ & & & $\begin{array}{l}\text { Unadjusted for } \\
\text { the potential } \\
\text { covariates }\end{array}$ \\
\hline $\begin{array}{l}\text { Swart et al. } 2016^{(37)} \\
\text { (B-PROOF study) } \\
\text { Longitudinal data }\end{array}$ & $\begin{array}{l}\text { To examine the effect of a 2-year supplementation of vita- } \\
\text { min } B_{12} \text {, folic acid and vitamin } D_{3} \text { on physical perfor- } \\
\text { mance, handgrip strength and risk of falling }\end{array}$ & $\begin{array}{l}2919 \text { elderly } \\
\text { (aged } \geq 65 \text { years) }\end{array}$ & $\begin{array}{l}\text { Double-blind, randomised, } \\
\text { placebo-controlled trial }\end{array}$ & & & \\
\hline Ao et al. $2017^{(38)}$ & $\begin{array}{l}\text { To study the relationship between Hcy and muscle } \\
\text { strength and physical performance }\end{array}$ & $\begin{array}{l}86 \\
\text { institutionalised elderly (mean } \\
\text { age } 85 \cdot 5 \pm 7 \cdot 4 \text { years). } \\
\text { Only women were analyzed } \\
\quad(n=65)\end{array}$ & Cross-sectional study & & $\begin{array}{l}\text { Only for muscle } \\
\text { strength; not for } \\
\text { limb muscle } \\
\text { strength }\end{array}$ & \\
\hline Granic et al. $2017^{(39)}$ & $\begin{array}{l}\text { To explore the prospective association between grip- } \\
\text { strength over } 5 \text { years and inflammatory components, } \\
\text { including Hcy levels }\end{array}$ & $\begin{array}{l}845 \text { elderly (mean age } 85.49 \pm \\
0.44 \text { years at baseline) of the } \\
\text { Newcastle } 85+\text { Study. }\end{array}$ & $\begin{array}{l}\text { Longitudinal study } \\
\text { (5-year follow-up) }\end{array}$ & & & \\
\hline $\begin{array}{l}\text { van Schoor et al. } \\
2012^{(42)} \\
\text { (LASA study) }\end{array}$ & $\begin{array}{l}\text { To examine whether high plasma Hcy and low serum vita- } \\
\text { min } B_{12} \text { were independent risk factors for lower physical } \\
\text { performance }\end{array}$ & $\begin{array}{l}1509 \text { elderly } \\
\text { (aged } \geq 65 \text { years) }\end{array}$ & $\begin{array}{l}\text { Longitudinal study } \\
\text { (3-year follow-up) }\end{array}$ & & & $\begin{array}{l}\text { Women } \\
\text { (baseline } \\
\text { and follow-up) }\end{array}$ \\
\hline
\end{tabular}

Legend. Green: significant association; red: no significant association; yellow: significant association only in particular circumstances referring to (i) sex (men and women), (ii) time of observations (baseline and follow-up), (iii) MTHFR genotype, and (iv) when unadjusted for the potential covariates; grey: not possible to conclude since only Hcy-metabolically related vitamins were assessed. 
significant increase in Hcy levels in sarcopenic elderly women when compared with control ones. Besides, neither Bulut et $a l^{(23)}$ nor Verlaan et $a l^{(24)}$ measured Hcy levels directly, assessing only metabolically related vitamins (e.g. vitamin $\mathrm{B}_{12}$ and/or folic acid) ${ }^{(23,24)}$. These studies were included in the present narrative review since the authors ${ }^{(23,24)}$ hypothesised a relationship between assumed increased Hcy levels and decreased muscle strength and physical performance (gait speed). However, although sarcopenic elderly reported significantly lower vitamin $\mathrm{B}_{12}$ levels, the assumption that an increase in Hcy levels could only be due to vitamin B deficiency is not exhaustive. It is well known ${ }^{(20)}$ that Hcy levels are affected by several conditions, including lifestyle factors, impaired kidney function, genetics and medications.

\section{Muscle mass}

Muscle mass can be estimated by different techniques ${ }^{(1)}$. Magnetic resonance imaging (MRI) and computed tomography (CT) are the gold standards for non-invasive muscle mass assessment ${ }^{(28)}$, even if cut-offs are not well defined ${ }^{(1)}$. Muscle mass can also be estimated directly by dual-energy X-ray absorptiometry $(\mathrm{DXA})^{(1)}$, or indirectly by bioelectrical impedance analysis (BIA). The EWGSOP2 Consensus reports that, considering affordability and portability, BIA-based determinations of muscle mass may be preferable to DXA ones, even if further studies are necessary to validate target-specific prediction equations ${ }^{(1)}$. The AGWS2 Consensus $^{(3)}$ recommends using either DXA or multifrequency BIA, both height-adjusted.

In general, muscle mass can be described as total body skeletal muscle mass (by MRI or BIA), as appendicular skeletal muscle mass or lean mass (by MRI, DXA and BIA) or as muscle cross-sectional area of specific muscle groups or body locations (by MRI or CT) ${ }^{(1)}$

Bulut and colleagues ${ }^{(23)}$ estimated lean body mass and skeletal muscle mass by BIA and calculated muscle mass index (muscle mass $/$ height ${ }^{2}$ ), which was considered low when below $8.87 \mathrm{~kg} / \mathrm{m}^{2}$ and $6.42 \mathrm{~kg} / \mathrm{m}^{2}$, respectively, for males and females ${ }^{(23)}$. Results showed that lean body mass, skeletal muscle mass and muscle mass index were significantly lower in patients with vitamin $\mathrm{B}_{12}$ deficiency (cut-off level $<400 \mathrm{pg} / \mathrm{ml}$ ), than in those with no deficiency $(p<0.05)^{(23)}$.

Swart et al. ${ }^{(29)}$ examined the baseline data $(n=1301$, aged $\geq 65$ years) and the longitudinal data (3-year follow-up; $n=1138$, aged $\geq 65$ years) obtained from the Longitudinal Aging Study Amsterdam (LASA) cohort after imputation of missing data. The intent was to explore Hcy levels about different aspects of physical functioning, including muscle mass, taking also into consideration sex as well as serum creatinine levels as possible confounders ${ }^{(29)}$. Particularly, at baseline and in the longitudinal model, no associations between quartiles of Hcy levels and muscle mass (assessed by DXA) were found; when the model was fully adjusted for all the other variables, including serum creatinine, sex, body mass index, region of living, level of education, alcohol consumption, smoking, and serum vitamin $\mathrm{B}_{12}$ concentration, results were similar ${ }^{(29)}$.

The same findings were also reported by Elshorbagy and colleagues ${ }^{(30)}$. Indeed, considering the Hordaland Homocysteine
Study $-\mathrm{I}^{(31)}$ and $-\mathrm{II}^{(32)}$, they investigated the association of plasma total Cysteine (tCys) and Hcy levels with lean and fat mass, assessed by DXA, in 7038 participants (including middle-age and elderly), also exploring whether changes in tCys and Hcy predicted body composition (lean mass, fat mass and BMI) over a period of 6 years ${ }^{(30)}$. Despite this study ${ }^{(30)}$, besides the elderly ( $n=3321)$, also considering middle-aged subjects $(n=3717)$, results were included in the present review. Cross-sectional data failed to describe Hcy relationship with lean mass when adjusted for other covariates such as tCys, B vitamins and lifestyle factors, including smoking, coffee consumption, physical activity and dietary intakes (i.e. total energy, protein and fat intakes); on the contrary, Hcy levels were significantly and inversely associated with BMI and fat mass, after adjustment for tCys ${ }^{(30)}$. Moreover, there was no significant association between change in Hcy levels over 6 years and BMI, lean mass and fat mass at follow-up. Besides, after including additional covariates in the models, only associations with BMI and fat mass were statistically significant $(p<0 \cdot 001)^{(30)}$.

Swart and colleagues ${ }^{(33)}$, considering baseline data of the BPROOF study (B-vitamins for the PRevention of OsteoporOtic Fractures), a large double-blind, randomised, placebo-controlled trial conducted on elderly population (2819 participants, aged $\geq 65$ years $)^{(34)}$, examined the association of plasma Hcy levels and MTHFR 677C-T polymorphism with muscle mass (by DXA), and possible confounders, including sex, creatinine, age, years of education, study location, BMI, lifestyle variables, vitamin $B_{12}$ and folic acid status. The authors reported no significant association between plasma Hcy levels and muscle mass ${ }^{(33)}$. Moreover, although increased plasma Hcy levels were observed in individuals with MTHFR 677TT genotype, this polymorphism was not associated with muscle mass decrease ${ }^{(33)}$.

Atkins et al. ${ }^{(35)}$ explored the association between low muscle mass and a wide range of lifestyle, dietary and cardiovascular risk factors (i.e. metabolic risk factors, markers of inflammation, endothelial dysfunction and coagulation, including Hcy levels) in 4252 men (aged 60-79 years) of the British Regional Heart Study cohort $(n=7735)$. The authors ${ }^{(35)}$ assessed muscle mass by using the mid-arm muscle circumference (MAMC) and calculated fat-free mass index $\left(\mathrm{FFMI}=\mathrm{FFM} /\right.$ height $^{2}$ ), defining low muscle mass as below the first quartile $(\leq 24.95 \mathrm{~cm}$ and $\leq 15.96 \mathrm{~kg} / \mathrm{m}^{2}$ for MAMC and FFMI, respectively). Although physical inactivity, insulin resistance, C-reactive protein, von Willebrand factor and fibrinogen were associated with significantly increased odds of low MAMC and FFMI, after adjustment for BMI, lifestyle habits and morbidity, no significant association was found between Hcy levels and MAMC and FFMI ${ }^{(35)}$.

Again, ter Borg et $a l .{ }^{(22)}$ using data collected from the MaSS cross-sectional study, investigated the association between markers of nutritional status (including Hcy) previously discussed and muscle mass parameters in a community-dwelling older adult ( $n=227$, aged $\geq 65$ years). Particularly, muscle mass was assessed by BIA ${ }^{(22)}$, and skeletal muscle mass was calculated according to the Janssen equation and then used to estimate skeletal muscle index (muscle mass $/$ height $^{2}$ ), according to the sex-relevant cut-off $\geq 6.75 \mathrm{~kg} / \mathrm{m}^{2}$ and $\geq 10.75 \mathrm{~kg} / \mathrm{m}^{2}$, respectively, in women and men ${ }^{(22)}$. The authors found a significant difference between Hcy quartiles and skeletal muscle 
index $^{(22)}$. Specifically, it was significantly lower $(p<0.05)$ in the lowest Hcy quartile $(\leq 9.4 \mu \mathrm{mol} / \mathrm{l})$ than in the other ones (9.4$11.6 \mu \mathrm{mol} / 1 ; 11.6-14.7 \mu \mathrm{mol} / \mathrm{l} ; \geq 14.7 \mu \mathrm{mol} / \mathrm{l})^{(22)}$. Moreover, participants in the highest Hcy quartile $(\geq 14.7 \mu \mathrm{mol} / \mathrm{l})$ had the highest SMI $(p=0.001)^{(22)}$. After adjustment for the potential covariates (i.e. sex, age, BMI, number of comorbidities and medications), significance disappeared ${ }^{(22)}$.

The cross-sectional population-based cohort study conducted by Lee $e t a l .{ }^{(26)}$ and considering the first wave of the I-Lan Longitudinal Aging Study (ILAS) investigated the association between two biomarkers of inflammation (serum Hcy and hsCRP levels) and three SA components (muscle mass, weakness assessing muscle strength and physical performance assessing walking speed) among community-living older adults $(n=1582 \text {, mean age } 64 \cdot 0 \pm 9 \cdot 2 \text { years })^{(26)}$. Muscle mass was measured by DXA. Appendicular skeletal muscle mass (the sum of the lean soft tissue mass of all four limbs) was calculated and height-adjusted to obtain muscle index (appendicular skeletal muscle mass/height $\left.{ }^{2}\right)^{(26)}$. Low muscle mass was defined as when muscle index was $<7 \mathrm{~kg} / \mathrm{m}^{2}$ and $<5.4 \mathrm{~kg} / \mathrm{m}^{2}$, respectively, for men and women ${ }^{(26)}$. Globally, in this study, the authors identified a significant association between increased levels of Hcy and both weakness and slowness but not with muscle mass ${ }^{(26)}$. Although Hcy levels were significantly $(p=0.022)$ higher in subjects with low muscle mass and the association of $\log (\mathrm{Hcy})$ per standard deviation increase was significant (OR 1.2; CI 1.0, 1.4; $p=0 \cdot 016$ ), no association was found for high levels of Hcy and muscle mass (OR 1.3; CI 0.8, 2.0; $p=0 \cdot 268$ ), even after adjustment for age, sex, education, relevant medications, smoking and Charlson Comorbidity Index (used to surrogate the burden of diseases) ${ }^{(26)}$.

In general, considering the studies mentioned in this paragraph, no association was found between increased Hcy levels and reduced muscle mass in most of the studies ${ }^{(26,29,30,33,35)}$.

The lack of this association could be due to different aspects. For instance, as described by Swart et al. ${ }^{(33)}$, subjects investigated by DXA were, in general, healthier and physically more active than those who were not. Another possible explanation is that, since muscle mass is related to creatine turnover, an increased Hcy formation could still be observed because the high lean mass entails a high turnover of creatine $^{(30,36)}$. Swart et al. ${ }^{(29,33)}$ also pointed out methodological aspects; for instance, the use of different DXA devices may have introduced a systematic distortion in the results of muscle mass measurement ${ }^{(33)}$; moreover, as suggested by Atkins et al. ${ }^{(35)}$ the use of indirect measurements of muscle mass (BIA, for instance) may have attenuated the associations. Besides, the lack of association could be also linked to (i) only one single measurement of Hcy levels because of the blood-sampling availability ${ }^{(29)}$ and (ii) muscle mass assessment measured at one time point ${ }^{(35)}$.

The positive association between Hcy and muscle mass has been described by ter Borg et al. ${ }^{(22)}$, despite disappearing after adjustment for the potential covariates. Only Bulut and colleagues ${ }^{(23)}$ reported a significant association, even if they did not measure Hcy levels directly, assuming increased Hcy levels due to vitamin $\mathrm{B}_{12}$ deficiency.

\section{Muscle strength}

Regarding muscle strength, EWGSOP2 recommends the use of grip strength and chair stand, both in clinical practice and research setting ${ }^{(1)}$. Particularly, grip strength is easier and less expensive than other muscle strength measures, and it correlates moderately with strength in other body compartments, so it serves as a reliable surrogate for more complicated measures of arm and leg strength ${ }^{(1)}$. EWGSOP2 recommends measuring maximum grip strength using a Jamar dynamometer, a validated and widely used hand-grip dynamometer ${ }^{(1)}$. Similarly, almost all studies in East and Southeast Asia that focused on muscle strength, function and SA have used handgrip strength to indicate skeletal muscle strength ${ }^{(3)}$. Therefore, AWGS2 ${ }^{(3)}$ retains a recommendable spring-type dynamometer (Smedley), followed by hydraulic-type (Jamar); however, since data generated from these dynamometers are not directly comparable, AWGS2 $2^{(3)}$ does not propose dynamometer-specific cut-off values since comparative data are scarce.

The potential mechanisms linking Hcy and muscle strength are various. For instance, increased Hcy levels could contribute to muscle strength decline through various pathologies that have inflammation as a common factor ${ }^{(16)}$. Moreover, increased Hcy levels could be responsible for muscle atrophy and a decrease in muscle strength through neurotoxicity and atherosclerosis ${ }^{(23)}$. Finally, vitamin $\mathrm{B}_{12}$ deficiency (one of the HHcy risk factors) could be responsible for the structural integrity of elastin, collagen and proteoglycans, with disruption leading to skeletalmuscle system disorders and decreased muscle strength ${ }^{(23)}$.

The present review reported eight studies ${ }^{(22,23,26,29,33,37-39)}$ exploring the association between increased Hcy levels and muscle strength taking into consideration different aspects including Hcy-metabolically related vitamins and other lifestyle factors influencing Hcy levels ${ }^{(22,23,29,37,38)}$, genetic polymorphism affecting Hcy levels ${ }^{(33)}$ and Hcy role as an inflammatory biomarker ${ }^{(26,39)}$.

In the cross-sectional study conducted by Bulut and collaborators ${ }^{(23)}$, the authors reported that dynapenia (defined as the reduction in muscle strength only) was more common than SA; among participants, $24.8 \%$ of subjects were diagnosed with SA and $32.0 \%$ with dynapenia. Moreover, in this cross-sectional study, the incidence of dynapenia was significantly higher in elderly with vitamin $B_{12}$ deficiency $(<400 \mathrm{pg} / \mathrm{ml})$ than in those without vitamin $B_{12}$ deficiency, assuming a possible inverse association between assumed increased levels of Hcy and muscle strength, since Hcy levels were not measured directly ${ }^{(23)}$.

Swart et al. ${ }^{(29)}$, in the LASA cohort study, aimed at examining Hcy levels in connection with muscle mass, grip strength, functional limits and falls, described a significant $(p<0.01)$ inverse association between increased Hcy levels and lower grip strength (assessed by a handheld dynamometer, Takei TKK 5001, Japan) only in men. The authors considered age, serum creatinine, BMI, region, years of education, alcohol use, and smoking and vitamin $\mathrm{B}_{12}$ levels, as possible confounders ${ }^{(29)}$. Furthermore, although the median change in grip strength over the 3 -year follow-up period was $-3.4 \mathrm{~kg}$, longitudinal analyses 
revealed no statistically significant associations between Hcy levels and grip strength in both men and women ${ }^{(29)}$.

The same authors ${ }^{(33)}$, in the B-PROOF study, evaluated also the genetic aspects of increased Hcy levels, investigating: (i) the association of Hcy levels and the MTHFR 677C-T polymorphism with muscle mass, handgrip strength, physical performance and postural sway, and (ii) the interaction between Hcy levels and the MTHFR 677C-T polymorphism - particularly, as regards muscle strength in subjects in the highest quartile of Hcy ( $\geq 16.9 \mu \mathrm{mol} / \mathrm{l}$ and $\geq 16.4 \mu \mathrm{mol} / 1$, for men and women, respectively), who showed a significantly lower $(p<0.01)$ handgrip strength (assessed by dynamometer, Takei, TKK 5401, Japan) than those in the first quartile (control group) ${ }^{(33)}$. Female sex was also identified as an effect modifier $(p=0.03)$; however, additional adjustments for serum vitamin B12 and folic acid concentration did not change the results ${ }^{(33)}$. No associations were found between MTHFR genotype and handgrip strength and Hcy-MTHFR genotype interaction ${ }^{(33)}$.

Again, from the B-PROOF project, Swart et al. ${ }^{(37)}$ examined the effect of a 2-year intervention study on vitamin $\mathrm{B}_{12}$ and folic acid supplementation and muscle strength (measured with a handheld dynamometer) in the elderly. The active group (1461 subjects) received 2-year supplementation with vitamin $\mathrm{B}_{12}(500 \mu \mathrm{g})$ folic acid $(400 \mu \mathrm{g})$ and vitamin D3: 600 IU correspond to $15 \mu \mathrm{g}$, while the control group (1458 subjects), received only vitamin $\mathrm{D}_{3}$ (600 IU) ${ }^{(37)}$. Smoking habits (former, current, no smoker), alcohol use (light, moderate, excessive), physical activity, education level (low, intermediate, high), $\mathrm{B}_{12}$ and/or folic acid supplementation use, and retrospective reports of falling, assessed using a questionnaire, were considered possible confounders ${ }^{(37)}$. The authors observed a significant 2 -year decline in both treatment groups $(p<0.01)$ with no significant differences. Linear mixed models reported no interaction effects, and adjustments for confounders did not change the findings. The change in Hcy levels after 2 years was not associated with follow-up handgrip strength ${ }^{(37)}$.

On the contrary, Ao et al. ${ }^{(38)}$ carried out a cross-sectional study on seventy-seven residents and users (mean age 83.5 years) of five care facilities, according to inclusion/exclusion criteria, aiming at investigating the association between physical performance, Hcy and metabolically related B-vitamins. These results have been reported in this paragraph since the physical performance was evaluated, besides gait speed (using short physical performance battery), assessed by handgrip strength (using a hand dynamometer, Digital Grip Dynamometer, Takey Scientific Instruments; Niigata, Japan) and quadriceps muscle strength (using Locomoscan TM, AlCare Co. LTd.; Tokyo, Japan) ${ }^{(38)}$. On account of the marked sex difference in muscle strength between men and women $(p<0 \cdot 001$, handgrip), only females were examined, being much more numerous ${ }^{(38)}$. According to the Hcy tertiles (1st: $9.5 \pm 1.2 \mu \mathrm{mol} / \mathrm{l}$; 2nd: $12 \cdot 8 \pm 0.9 \mu \mathrm{mol} / \mathrm{l}$; 3rd: $18 \cdot 7 \pm 3 \cdot 2 \mu \mathrm{mol} / \mathrm{l})$, ANOVA followed by Tukey's multiple comparison test reported a significant difference between the first and the third tertile in handgrip strength $(p=0.027)^{(38)}$. However, even if limb muscle strength in the third tertile $(0.31 \pm 0.13 \mathrm{kgf})$ was higher than in the second one $(0.34$ $\pm 0.18 \mathrm{kgf})$ and the first one $(0.45 \pm 0.20 \mathrm{kgf})$, no significance was reached $(p=0.066)^{(38)}$. Furthermore, multiple regression analysis was performed to study the factors contributing to muscle strength using independent variables age, skeletal muscle mass percentage, serum albumin, folate, vitamin $B_{12}$ levels and plasma Hcy levels. Only age and folate levels were significantly related to handgrip strength $(\beta=-0.04, \quad p=0.002$; $\beta=0.247, p=0.03$, respectively) and limb muscle strength $(\beta=-0.316, p=0.035 ; \beta=0.327, p=0.024 \text {, respectively })^{(38)}$.

Ter Borg ${ }^{(22)}$, investigating the association between markers of nutritional status and muscle parameters, did not find a significant association between Hcy levels (included as an indirect nutrient status marker for the B vitamins) and muscle strength in the MaSS study population ( $n=227$, aged $\geq 65$ years). Indeed, muscle strength did not differ significantly among the Hcy quartiles ( $\leq 9.4 \mu \mathrm{mol} / 1,9.4-11.6 \mu \mathrm{mol} / 1,11.6-14.7 \mu \mathrm{mol} / \mathrm{l}$, $\geq 14.7 \mu \mathrm{mol} / \mathrm{l})^{(22)}$. In this case, muscle strength was assessed using a dynamometer and considered poor if $<20 \mathrm{~kg}$ or $<30 \mathrm{~kg}$, respectively, for women and men, according to the old European consensus ${ }^{(4)}$.

Granic et al. ${ }^{(39)}$ for the first time investigated prospectively the relationship between summary variables of inflammation and muscle strength in 845 participants (aged over 85 years) from the longitudinal Newcastle $85+$ Study. For this purpose, the authors used mixed models to explore the prospective association between muscle strength (assessed by hand dynamometer, Takei Scientific Instruments Co., Ltd., Niigata, Japan; and assuming the cut-offs for weakness of $\leq 27 \mathrm{~kg}$ and $\leq 16 \mathrm{~kg}$ for men and women, respectively) over 5 years and inflammatory components, identified by principal component analysis ${ }^{(39)}$. Three components explaining $70 \%$ of the variance in the inflammatory variables were identified: basal interleukin- 6 and tumour necrosis factor- $\alpha$ had the highest loadings on component 1 (34.9\%); stimulated interleukin- 6 and tumour necrosis factor- $\alpha$ and Hcy had the highest loadings on component 2 (19.6\%); hsCRP loaded positively and albumin negatively to component $3(16.6 \%)^{(39)}$. However, in adjusted mixed models, only component 3 (hsCRP and albumin) was significantly associated with muscle strength at baseline, highlighting how the synergistic and cumulative effect of these markers may have exacerbated pathways contributing to greater muscle catabolism and reduced myogenesis ${ }^{(39)}$.

Moreover, considering the pro-inflammatory role of Hcy, Lee and colleagues ${ }^{(26)}$ explored the association between Hcy levels, hsCRP, SA and its components in a community-living elderly ( $n=1582$, mean age $64 \cdot 0 \pm 9 \cdot 2$ years) enrolled in the ILAS study. Muscle strength was detected using handgrip (Smedlay's Dynamo Meter; TTM, Tokyo, Japan), and cut-off values for weakness were considered both for men (muscle strength $\leq 28 \mathrm{~kg}$ ) and women (muscle strength $\leq 18 \mathrm{~kg}$ ) ${ }^{(26)}$. In general, this study confirmed the relationship between increased Hcy levels and hsCRP and SA. Besides, muscle strength was inversely and significantly associated both with Hcy $(p<0 \cdot 001)$ and with hsCRP levels $(p=0.002)^{(26)}$. These associations were stronger in younger subjects, women, non-smokers and those with lower multimorbidity burden for high serum levels of $\mathrm{Hcy}^{(26)}$. In the crude association between hsCRP/Hcy and three components of SA, low muscle strength was associated with (i) log Hcy per 
standard deviation increase (OR 1.4; CI 1.2, 1.6; $p<0.001$ ); (ii) high serum levels of Hcy (OR 2.9; CI $2 \cdot 1,4 \cdot 0 ; p<0 \cdot 001$ ); (iii) log hsCRP per standard deviation increase (OR 1.2 ; CI $1 \cdot 1,1 \cdot 4 ; p<0 \cdot 004$ ) and high hsCRP levels (OR 1.6; CI 1.2, 2.0; $p=0 \cdot 001)^{(26)}$. Besides, contrarily to the other two SA components (muscle mass and physical performance), also after adjustment for age, sex, education, relevant medications, smoking and Charlson Comorbidity Index, high levels of Hcy and hsCRP were still independently associated with weakness (Hcy levels: OR 1.6; $95 \%$ CI 1.1, 2.4; $p=0 \cdot 017$; hsCRP levels: OR 1.4; $95 \%$ CI $1.1,1 \cdot 9 ; p=0 \cdot 020)^{(26)}$.

Considering the results reported in this section, it is difficult to draw consistent conclusions. Sex was identified as an effect modifier in the association between Hcy and muscle strength in two studies ${ }^{(29,33)}$ where the significant and inverse association between increased Hcy levels and reduced muscle strength was observed for men in the LASA study cohort (data at baseline) ${ }^{(29)}$ and women in the B-PROOF study cohort (data at baseline) $)^{(33)}$. No association was reported between Hcy and muscle strength by others ${ }^{(22,37)}$. Bulut and colleagues ${ }^{(23)}$ described vitamin $\mathrm{B}_{12}$ deficiency in the elderly with reduced muscle strength, but Hcy levels were not measured directly, as already reported above. Only two studies conducted by Ao and colleagues ${ }^{(38)}$ and Lee and colleagues ${ }^{(26)}$ stated a significant association between reduced muscle strength and increased Hcy levels, even if this association was not confirmed when limb muscle strength was evaluated ${ }^{(38)}$. The lack of significant association between increased Hcy levels and decreased muscle strength could be due to differences between the cohorts. First of all, among the studies mentioned above ${ }^{(22,23,26,29,33,37,38,39)}$, weakness was defined according to different sex-related cut-offs. Then, cohorts were not age-homogeneous; in general, the average age was approximately 74 years $^{(22)}$ or lower ${ }^{(26,29,33,37)}$, but the average age in Ao et al. ${ }^{(38)}$ and Granic et al. ${ }^{(39)}$ cohort was 85 years, and it is acknowledged that age plays a key role in SA and frailty development. Also, some of them were community-dwelling subjects ${ }^{(22,26)}$, while others were institutionalised ${ }^{(38)}$.

\section{Performance}

In the EWGSOP2(1) besides muscle strength and quantity, low physical performance predicts adverse outcomes; when muscle strength, quantity/quality and physical performance are low, SA is considered severe ${ }^{(1)}$. The AWGS2 consensus $^{(3)}$ states that physical performance is a criterion for SA diagnosis in the concomitant presence of skeletal muscle loss, thus maintaining the original SA definition of 'age-related loss of skeletal muscle mass plus loss of muscle strength and/or reduced physical performance'. Also, similarly to EWGSOP2(1), subjects with muscle mass loss, poor muscle strength and low physical performance are classified as affected by 'severe sarcopenia'(3).

As AWGS2 ${ }^{(3)}$, IWGS ${ }^{(2)}$ reports that SA diagnosis is consistent with reduced physical performance and objectively measured muscle mass loss.

Physical performance is a multidimensional concept that is defined as an objectively measured whole-body function related to locomotion and that involves not only muscles but also central and peripheral nerve function, including balance ${ }^{(1)}$. It can be assessed by using different tests such as gait speed (e.g. 4-m or 400-m walk test), the Short Physical Performance Battery (SPPB) and the Timed-Up and Go test ${ }^{(1)}$. EWGSOP2 ${ }^{(1)}$ suggests gait speed (4-m walk test) for physical performance evaluation in the clinical setting since it is a quick, safe and highly reliable test; a single cut-off speed $\leq 0.8 \mathrm{~m} / \mathrm{s}$ is reported as an indicator of severe SA. The AWGS2 recommends using the usual gait speed to define reduced physical performance and has increased the cut-off from less than 0.8 to less than $1.0 \mathrm{~m} / \mathrm{s}^{(3)}$.

The association between increased plasma Hcy levels and decreased physical performance could be due to the effects of high Hcy levels on vascular neurologic and skeletal systems, impairing mobility and gait ${ }^{(40,41)}$; but it is still under debate.

Swart and colleagues ${ }^{(33)}$, starting from the baseline data of the B-PROOF randomised controlled trial, examined also the association of Hcy plasma levels and MTHFR 677C-T polymorphism with physical performance. Specifically, physical performance was investigated by using (i) walking test (the time needed to walk $3 \mathrm{~m}$ back and forth as quickly as possible), (ii) chair stands (the measurement of the time needed to stand up from and sit down on a chair for five successive times, without using hands) and (iii) tandem stand (the ability to stand with the feet right in front of each other for $10 \mathrm{~s}$ with eyes open) ${ }^{(33)}$. Results at baseline reported that subjects in the highest Hcy quartile had a lower physical performance score $(p=0 \cdot 01)$, compared with subjects in the lowest Hcy quartile; a significant interaction effect between plasma Hcy and female sex was also reported $(p=0.05)^{(33)}$. These associations were independent of vitamin B12 and folic acid status, and no such associations were found in men ${ }^{(33)}$. Considering the genotyping, association of MTHFR genotype with physical performance was not found ${ }^{(33)}$; increased plasma Hcy levels in 677CC and 677CT, but not in 677TT genotype, were significantly $(p<0.01)$ associated with the lower physical performance ${ }^{(33)}$.

Again, in the B-PROOF study, Swart and colleagues ${ }^{(37)}$, investigated the effect of a 2-year intervention with daily vitamin B12 and folic acid supplementation on changes in physical performance in a mildly hyperhomocysteinemic elderly population. The authors ${ }^{(37)}$ reported no overall effect post 2 -year daily B vitamin supplementation on physical performance among elderly persons with mild HHcy (cut-off value $\geq 18 \mu \mathrm{M}$ ); the results provided only indications of a trend towards a positive effect of the intervention on physical performance among compliant persons $>80$ years $^{(37)}$.

Swart and colleagues ${ }^{(29)}$ also explored the cross-sectional and longitudinal data (3-year follow-up) of the LASA study, focusing on physical performance. Particularly, they assessed functional limitations, by using a six-item questionnaire (derived from the validated OECD questionnaire) on the degree of difficulties in climbing stairs, using transportation, cutting their toenails, (un) dressing, rising from a chair, and walking outside for $5 \mathrm{~min}(0=$ no difficulty, to $4=$ unable); the total score on functional limitations ranged from 0 to 24 , with a score of 0 when no difficulties were reported and a score of 24 when respondents could not perform any of the activities ${ }^{(29)}$. The study results showed that the fourth quartile of Hcy levels was significantly associated with more functional limitations as compared with the first quartile 
(control), after adjustment for vitamin B12, in men, while in women, the longitudinal analyses showed that the fourth quartile of Hcy levels was associated with more functional limitations 3 years later as compared with the first quartile $\mathrm{e}^{(29)}$.

Again within the LASA cohort, van Schoor and colleagues ${ }^{(42)}$ examined whether high plasma Hcy and low serum vitamin $\mathrm{B}_{12}$ were risk factors for lower physical performance, both cross-sectionally and longitudinally. The authors ${ }^{(42)}$ concluded that increased plasma Hcy levels were independently related to the physical performance in older women. They observed that women in the highest quartile of Hcy had a significantly lower physical performance with a two-fold higher risk of decline than those in the lowest quartile both in the cross-sectional and in the longitudinal analyses ${ }^{(42)}$. For vitamin $\mathrm{B}_{12}$ in women, and Hcy and vitamin $\mathrm{B} 12$ in men, the observed associations were less consistent $^{(42)}$.

Ter Borg and colleagues ${ }^{(22)}$ from the MaSS protocol $(n=227$, aged $\geq 65$ years) also analyzed the association between different biomarkers of nutritional status, including Hcy, and physical performance assessed by a 4-m gait speed test and five times chair stand test. Gait speed was defined as slow when $\leq 0.8 \mathrm{~m} / \mathrm{s}$ following the old European consensus ${ }^{(4)}$. The authors described that subjects in the highest Hcy levels quartile $(\geq 14.7 \mu \mathrm{mol} / \mathrm{l})$ had lower gait speed $(p=0.001)$ and needed more time to complete their chair stand test than those in the lower ones (9.4$11.6 \mu \mathrm{mol} / 1 ; 11.6-14.7 \mu \mathrm{mol} / 1 ; 11.6-14.7 \mu \mathrm{mol} / 1, p=0.049)^{(22)}$. However, after adjustment for the potential covariates (age, BMI, sex, number of comorbidities and therapies), no associations remained ${ }^{(22)}$.

Also, Lee et al. ${ }^{(26)}$ explored the association between biomarkers of inflammation (serum Hcy and hsCRP) and physical performance among community-living older adults $(n=1582$, mean age $64 \cdot 0 \pm 9 \cdot 2$ years) enrolled in the ILAS protocol. In this case $^{(26)}$, physical performance was determined by a 6-m walk test, and subjects who walked slower than $1.0 \mathrm{~m} / \mathrm{s}$ were defined as having slow walking speed ${ }^{(3)}$. Results indicated that serum levels of Hcy were significantly higher among subjects with low physical performance $(p=0 \cdot 040)^{(26)}$. Also, in the crude association, increased Hcy levels were significantly associated with slowness (OR 2.0; $95 \%$ CI 1.3, 3.0; $p=0 \cdot 003$ ). However, similarly to ter Borg et al. ${ }^{(22)}$, this significant association was not confirmed after adjustment for age, sex, education, relevant medications, smoking and Charlson Comorbidity Index ${ }^{(26)}$.

Finally, Ao and colleagues ${ }^{(38)}$ in their cross-sectional study conducted on community-dwelling older adults ( $n=77$, mean age 83.5 years; analysis conducted only on females) explored the association between Hcy and metabolically related vitamins and indices of physical performance. In this case, physical performance was evaluated by assessing not only gait speed but limb muscle strength and muscle strength ${ }^{(38)}$. In this paragraph, we considered only results concerning gait speed since the other two indices were already presented, where appropriate, in the previous paragraph. Particularly, the authors reported no significant differences in gait speed among tertiles of plasma Hcy levels $(1.2 \pm 0.4 \mathrm{~m} / \mathrm{s} ; 1.1 \pm 0.3 \mathrm{~m} / \mathrm{s} ; 0.9 \pm 0.4 \mathrm{~m} / \mathrm{s}$, $p=0.435)^{(38)}$.

Previous findings described a reduced physical functioning and accelerated mobility decline in the elderly showing increased plasma Hcy levels ${ }^{(40,41)}$; thus, HHcy could be considered a potentially modifiable risk factor for mobility decline ${ }^{(43)}$. Van Schoor and colleagues ${ }^{(42)}$ provided different mechanisms explaining the association between Hcy levels and physical performance. First of all, increased Hcy levels induce an increase in inflammatory status and cytokine responses inhibiting repair after muscle tissue injury, thus promoting muscle proteolysis $^{(42)}$. Second, it has been demonstrated that a high level of Hcy may lead to impaired cognitive function or dementia and fractures contributing to lower physical performance ${ }^{(42)}$. Finally, the increase of Hcy levels is related to an increase in white-matter hyper-intensities, which have been related to lower extremity function ${ }^{(42)}$. In general, considering the inverse association between Hcy levels and physical performance, out of seven studies ${ }^{(22,26,29,33,37,38,42)}$, three of them ${ }^{(29,33,42)}$ partly confirmed this association but with a sex influence in most of the cases. A stronger and significant association has been described between increased total Hcy levels and lower physical performance in women both at baseline ${ }^{(29,33)}$ and during followup $^{(33,42)}$. However, further studies are needed to confirm this finding. Besides, others ${ }^{(22,38)}$ reported a significant association only when the analysis was not adjusted for potential covariates. Thus, as reported for the other two SA components, the association between increased Hcy levels and reduced physical performance remains undebated.

\section{Discussion}

SA can be considered as a geriatric syndrome due to physiological and functional decline in skeletal muscle tissue, increasing morbidity, direct and indirect health care costs and mortality ${ }^{(1)}$. Since SA seems to be associated with other comorbidities such as osteoporosis, falls, frailty and dementia, this suggests that it is more than simple muscle strength and muscle quantity/ quality loss; rather, it is a clinical condition involving complex mechanisms ${ }^{(1)}$.

Both 'muscle-specific' and 'non-muscle-specific' biomarkers have been identified in $\mathrm{SA}^{(44)}$. The specific biomarker is defined as a marker that should ideally be able to evaluate muscle strength loss and muscle mass, such as procollagen type III Nterminal peptide, 3-methylhistidine, VI collagen N-terminal globular domain epitope, MMP-generated degradation fragment of collagen 6 , and the skeletal muscle-specific isoform of tropo$\operatorname{nin} \mathrm{T}$, cardiac troponin $\mathrm{T}^{(44)}$. However, in the last years, studies have raised doubts about the specificity of these markers in detecting $\mathrm{SA}^{(44)}$. Among 'non-muscle-specific' biomarkers, there are molecules involved in mechanisms underlying the ageing process, such as (i) markers of inflammation (e.g. C-reactive protein, interleukin- 6 , interleukin-8, tumour necrosis factor- $\alpha$, interferon- $\gamma$, granulocyte-monocyte colony-stimulating factor); (ii) markers of oxidative damage (e.g. advanced glycation end products); (iii) markers of nutritional status (e.g. leptin, vitamin D); (iv) markers of the endocrine system (e.g. dehydroepiandrosterone sulfate, growth hormone, insulin-like growth factor 1); (v) markers related to growth factors (e.g. growth differentiation factor-15, transforming growth factor- $\beta$; and (vi) markers of neuromuscular junction dysfunction (C-terminal 22-kDa fragment derived from the proteolytic cleavage of agrin) ${ }^{(44)}$. 
'Non-muscle-specific' biomarkers could be modified by lifestyle factors, comorbidity, diseases and exposure to drugs ${ }^{(44)}$.

It has been also previously reported that HHcy is associated with SA and could mediate proliferation inhibition of the satellite cell (resident muscle precursor/stem cells with regenerative capacities properties) by (i) enhancing the p38 MAPK signalling in different tissue types; (ii) enhancing the oxidative damage in skeletal muscles; and (iii) inducing myostatin, an inhibitor of myogenesis, in skeletal muscles ${ }^{(45)}$. Veeranki and colleagues ${ }^{(45)}$ demonstrated in in vivo models (cystathionine- $\beta$-synthase ${ }^{-/+}$mouse) that HHcy exhibited compromised regenerative function and cell proliferation upon injury, potentially becoming a therapeutic target for elderly frailty.

This review analyzed for the first time the association of increased Hcy levels in SA and its components, such as muscle mass, muscle strength and physical performance. However, as shown in Tables 2 and 3, the results are conflicting.

In Table 2, positive association between increased Hcy levels and $\mathrm{SA}^{(22,26)}$ is reported only in the studies conducted by ter Borg et $a l .{ }^{(22)}$ and Lee et al. ${ }^{(26)}$; other authors either reported no significant association ${ }^{(25)}$ or measured only Hcy-metabolically related vitamins, assuming that increased Hcy levels could be due to vitamin $\mathrm{B}$ deficiency ${ }^{(23,24)}$. Therefore, it is not possible to speculate about the association between increased Hcy levels and the presence of SA, regardless of the diagnostic criteria adopted (Table 1).

Table 3 presents Hcy levels related to SA components (muscle mass, muscle strength and physical performance), which mutually contradict, except for muscle mass, which showed no significant associations with Hcy levels in most of the studies ${ }^{(26,29,30,33,35)}$. Otherwise, results concerning associations between Hcy levels and muscle strength or physical performance were heterogeneous. Concerning muscle strength in the LASA baseline data, a significant association was observed only in men ${ }^{(29)}$. On the contrary, the B-PROOF baseline data ${ }^{(33)}$ showed a significant relationship between increased Hcy levels and decreased muscle strength only in women; however, this association was lost in the longitudinal analysis ${ }^{(37)}$. Ao and colleagues ${ }^{(38)}$ reported a significant relationship only when results were unadjusted for potential covariates, while ter Borg ${ }^{(22)}$ did not show any significant result. The only study reporting a significant relationship between high levels of Hcy and low muscle strength was the prospective population-based study by Lee et $a l{ }^{(26)}$. The same situation was depicted also for physical performance that showed a significant association only if sex-related $^{(29,33,42)}$ or unadjusted for potential covariates ${ }^{(22)}$.

The B-PROOF study ${ }^{(33)}$ analysed the MTHFR $677 \mathrm{C}-\mathrm{T}$ polymorphism related to physical performance and muscle function in a large sample of older persons, showing that this polymorphism was not related to physical outcomes in older persons, in contrast to plasma Hcy levels ${ }^{(33)}$. These results were also corroborated by the homocysteine-gene interaction analysis expecting an association in all genotypes whenever plasma Hcy levels were elevated, and especially in 677TT genotype associated with higher plasma Hcy concentrations ${ }^{(33)}$. However, no association with MTHFR genotype and no interaction effect was highlighted for muscle strength and physical performance except for the interaction effect in 677CC and 677CT genotype as far as physical performance is concerned ${ }^{(29,33)}$.

\section{Conclusions}

In the past decade, the association between Hcy and physical function has been examined both in cross-sectional and longitudinal observational studies(22-26,29,30,35,37-39,42) showing that increased Hcy levels are related to accelerated decline in mobility and muscle strength, suggesting a potential association between HHcy and SA. However, despite a non-systematic literature approach, in this present review, few and conflicting data emerged about the association between SA and increased Hcy levels.

These inconsistencies, leading to contradictive conclusions, could also be due to differences among studies concerning (i) cut-offs adopted for muscle mass, muscle strength and physical performance evaluation; (ii) community-dwelling elderly versus institutionalised ones; (iii) ethnicity and sex differences in skeletal muscle kinetics and fibre composition; and (iv) ethnicity differences in MTHFR mutation prevalence.

Furthermore, looking at intervention studies, such as the BPROOF study ${ }^{(37)}$, it is noteworthy to point out that the lack of a significant association between improvement in SA components (such as muscle strength and physical performance) and reduction Hcy levels after supplementation may be due to adequate baseline vitamin status. For this reason, the intervention may not be effective, and therefore the results must also be considered in light of the basal levels of micronutrients.

Again, since there are no concrete definitions of 'elderly' that appropriately characterise the population, the mean age of cohorts' participants differed widely. Indeed, ageing, an inevitable process, is commonly measured by chronological age, and, as a convention, a person aged 65 years or more is often referred to as 'elderly'. However, there is no clear medical or biological evidence to support this definition; the ageing process is not uniform across the population owing to differences in genetics, lifestyle and overall health ${ }^{(46)}$. Thus, chronological age fails to address the heterogeneity observed among the 'elderly' of the studies reported in the present review. Besides, since increased Hcy levels could result from the decline of the glomerular filtration rate with increasing age, and because of the higher incidence of renal impairment in the elderly, the Hcy concentrations must be interpreted with caution in this population $^{(19,20)}$.

Finally, factors associated with HHcy (e.g. enzyme mutations, vitamin B group levels, lifestyle factors, sex and age, antioxidants) should be considered when investigating associations between SA and Hcy levels, since they can function as confounding factors, changing the meaning and significance of the association of Hcy and SA, as well as with muscle strength, muscle mass and physical performance.

Therefore, we feel that further studies are still needed to clarify these issues, taking into consideration all the possible confounders mentioned above; a meta-analysis of this topic could be also carried out in the future because not all studies should contribute in the same way to the conclusion reached by us. 


\section{Acknowledgements}

The authors are very grateful to Dr Beatrice Vigo, Dr Maria Vittoria Conti, Dr Valentina Braschi who actively participated in the Food Social Sensor Network (Food NET) project.

\section{Conflicts of Interest}

The authors declare no conflict of interest.

\section{Author Contributions}

Conceptualisation: R.D.G.; methodology: R.D.G., C.E.T., A.V. and I.D.N.; writing, original draft preparation: R.D.G., C.E.T. and A.V.; writing, review and editing: R.D.G., A.V., M.N. and H.C.; supervision: H.C. All authors have read and agreed to the published version of the manuscript.

\section{Funding}

This research was funded by the Food Social Sensor Network (Food NET) project - Research and Innovation, co-funded by POR FESR 2014-2020 - CUP E47F17000020009.

\section{References}

1. Cruz-Jentoft AJ, Bahat G, Boirie Y et al. (2019) Sarcopenia: revised European consensus on definition and diagnosis. Age Ageing 48, 16-31.

2. Fielding RA, Vellas B, Evans WJ et al. (2011) Sarcopenia: an undiagnosed condition in older adults. Current consensus definition: prevalence, etiology, and consequences. International working group on sarcopenia. J Am Med Dir Assoc 12, 249-56.

3. Chen LK, Woo J, Assantachai P et al. (2020) Asian Working Group for Sarcopenia: 2019 Consensus Update on Sarcopenia Diagnosis and Treatment. J Am Med Dir Assoc 21, 300-307.e2

4. Cruz-Jentoft AJ, Baeyens, JP, Bauer JM et al. (2010) Sarcopenia: European consensus on definition and diagnosis: Report of the European Working Group on Sarcopenia in Older People. Age Ageing, 39, 412-23.

5. Chen LK, Liu LK, Woo J et al. (2014) Sarcopenia in Asia: consensus report of the Asian Working Group for Sarcopenia. J Am Med Dir Assoc 15, 95-101.

6. Landi F, Liperoti R, Russo A et al. (2012) Sarcopenia as a risk factor for falls in elderly individuals: results from the ilSIRENTE study. Clin Nutr 31, 652-658.

7. Edwards MH, Dennison EM, Aihie Sayer A et al. (2015) Osteoporosis and sarcopenia in older age. Bone, 80, 126-130.

8. Di Monaco M, Castiglioni C, De Toma E et al. (2015) Presarcopenia and sarcopenia in hip-fracture women: prevalence and association with ability to function in activities of daily living. Aging Clin Exp Res 27, 465-472.

9. Petermann-Rocha F, Chen M, Gray SR et al. (2019) New versus old guidelines for sarcopenia classification: what is the impact on prevalence and health outcomes? Age Ageing 49, 300-304.

10. Chang KV, Hsu TH, Wu WT et al. (2016) Association between sarcopenia and cognitive impairment: a systematic review and meta-analysis. J Am Med Dir Assoc 17, 1164.e7-1164.e15.
11. Tsekoura M, Kastrinis A, Katsoulaki M et al. (2017) Sarcopenia and its impact on quality of life. Adv Exp Med Biol 987, 213-218.

12. Batsis JA, Mackenzie TA, Barre LK et al. (2014) Sarcopenia, sarcopenic obesity and mortality in older adults: results from the National Health and Nutrition Examination Survey III. EurJ Clin Nutr 68, 1001-7.

13. Marzetti E, Calvani R, Tosato M et al. (2017) Sarcopenia: an overview. Aging Clin Exp Res 29, 11-17.

14. Lorenzo I, Serra-Prat M, Yébenes JC (2019) The role of water homeostasis in muscle function and frailty: a review. Nutrients 11, 1857.

15. Landi F, Calvani R, Tosato M et al. (2016) Protein intake and muscle health in old age: from biological plausibility to clinical evidence. Nutrients $\mathbf{8}, 295$.

16. Vidoni ML, Pettee Gabriel K, Luo ST et al. (2018) Relationship between homocysteine and muscle strength decline: The Baltimore Longitudinal Study of Aging. J Gerontol A Biol Sci Med Sci 73, 546-551.

17. Porter K, Hoey L, Hughes CF et al. (2016) Causes, consequences and public health, implications of low B-vitamin status in ageing. Nutrients $\mathbf{8}, 725$.

18. De Giuseppe R, Venturelli G, Guez S et al. (2016) Homocysteine metabolism in children and adolescents with epidermolysis bullosa. BMC Pediatr 16, 173.

19. EFSA NDA Panel (EFSA Panel on Dietetic Products, Nutrition and Allergies) (2014) Scientific opinion on dietary reference values for folate. EFSA J 12, 3893.

20. Malinowska J, Kolodziejczyk J, Olas B. (2012) The disturbance of hemostasis induced by hyperhomocysteinemia; the role of antioxidants. Acta Biochim Pol 59, 185-94.

21. Refsum H, Smith AD, Ueland PM et al. (2004) Facts and recommendations about total homocysteine determinations: an expert opinion. Clin Chem 50, 3-32.

22. ter Borg S, de Groot LC, Mijnarends DM et al. (2016) Differences in nutrient intake and biochemical nutrient status between sarcopenic and nonsarcopenic older adults - results from the Maastricht Sarcopenia Study. J Am Med Dir Assoc 17, 393-401.

23. Ates Bulut E, Soysal P, Aydin AE et al. (2017) Vitamin B12 deficiency might be related to sarcopenia in older adults. Exp Gerontol 95, 136-140.

24. Verlaan S, Aspray TJ, Bauer JM et al. (2017) Nutritional status, body composition, and quality of life in community-dwelling sarcopenic and non-sarcopenic older adults: a case-control study. Clin Nutr 36, 267-274.

25. Eguchi $\mathrm{Y}$, Toyoguchi T, Inage K et al. (2019) Advanced glycation end products are associated with sarcopenia in older women: aging marker dynamics. $J$ Women Aging 26, 1-13.

26. Lee WJ, Peng LN, Loh CH et al. (2020) Sex-different associations between serum homocysteine, high-sensitivity C-reactive protein and sarcopenia: results from I-Lan Longitudinal Aging Study. Exp Gerontol 132, 110832.

27. Janssen I, Baumgartner RN, Ross R et al. (2004) Skeletal muscle cutpoints associated with elevated physical disability risk in older men and women. Am J Epidemiol 159, 413-421.

28. Beaudart C, Zaaria M, Pasleau F et al. (2017) Health outcomes of sarcopenia: a systematic review and meta-analysis. PloS One 12, e0169548.

29. Swart KM, van Schoor NM, Heymans MW et al. (2013) Elevated homocysteine levels are associated with low muscle strength and functional limitations in older persons. $J$ Nutr Health Aging 17, 578-84.

30. Elshorbagy AK, Nurk E, Gjesdal CG et al. (2008) Homocysteine, cysteine, and body composition in the Hordaland Homocysteine Study: does cysteine link amino acid and lipid metabolism? Am J Clin Nutr 88, 738-46. 
31. El-Khairy L, Ueland PM, Nygard O et al. (1999) Lifestyle and cardiovascular disease risk factors as determinants of total cysteine in plasma: the Hordaland Homocysteine Study. Am JClin Nutr 70, 1016-24.

32. Refsum H, Nurk E, Smith AD et al. (2006) The Hordaland Homocysteine Study: a community-based study of homocysteine, its determinants, and associations with disease. J Nutr 136, Suppl. 6, 1731S-40S.

33. Swart KM, Enneman AW, van Wijngaarden JP et al. (2013) Homocysteine and the methylenetetrahydrofolate reductase $677 \mathrm{C}->\mathrm{T}$ polymorphism in relation to muscle mass and strength, physical performance and postural sway. Eur J Clin Nutr 67, 743-8.

34. van Wijngaarden JP, Dhonukshe-Rutten RA, van Schoor NM et al. (2011) Rationale and design of the B-PROOF study, a randomized controlled trial on the effect of supplemental intake of vitamin B12 and folic acid on fracture incidence. BMC Geriatr 11, 80 .

35. Atkins JL, Whincup PH, Morris RW et al. (2014) Low muscle mass in older men: the role of lifestyle, diet and cardiovascular risk factors. J Nutr Health Aging 18, 26-33.

36. McCarty MF (2001) Supplemental creatine may decrease serum homocysteine and abolish the homocysteine 'gender gap' by suppressing endogenous creatine synthesis. Med Hypotheses 56, 5-7.

37. Swart KMA, Ham AC, van Wijngaarden JP et al. (2016); A randomized controlled trial to examine the effect of 2-year vitamin B12 and folic acid supplementation on physical performance, strength, and falling: additional findings from the B-PROOF Study. Calcif Tissue Int 98, 18-27.
38. Ao M, Inuiya N, Ohta J et al. (2019) Relationship between homocysteine, folate, vitamin B12 and physical performance in the institutionalized elderly. J Nutr Sci Vitaminol 65, 1-7.

39. Granic A, Davies K, Martin-Ruiz C et al. (2017) Grip strength and inflammatory biomarker profiles in very old adults. Age Ageing 46, 976-982.

40. Kuo HK, Liao KC, Leveille SG et al. (2007) Relationship of homocysteine levels to quadriceps strength, gait speed, and late- life disability in older adults. J Gerontol A Biol Sci 62, 434-9.

41. Leishear K, Ferrucci L, Lauretani F et al. (2012) Vitamin B12 and homocysteine levels and 6-year change in peripheral nerve function and neurological signs. J Gerontol $67 \mathrm{~A}$, $537-543$.

42. van Schoor NM, Swart KM, Pluijm SM et al. (2012) Cross-sectional and longitudinal association between homocysteine, vitamin B12 and physical performance in older persons. Eur J Clin Nutr 66, 174-81.

43. Rolita L, Holtzer R, Wang C et al. (2011) Homocysteine and mobility in older adults. J Am Geriatr Soc 58, 545-550.

44. Casati M, Costa AS, Capitanio D et al. (2019) The biological foundations of sarcopenia: established and promising markers. Front Med 6, 184.

45. Veeranki S, Lominadze D, Tyagi SC (2015) Hyperhomocysteinemia inhibits satellite cell regenerative capacity through p38 alpha/beta MAPK signaling. Am J Physiol Heart Circ Physiol 309, H325-34.

46. Ouchi Y, Rakugi H, Arai H et al. (2017) Joint Committee of Japan Gerontological Society (JGLS) and Japan Geriatrics Society (JGS) on the definition and classification of the elderly. Geriatr Gerontol Int 17,1045-1047. 